S1 File. Survey questions as published (Danish and English).

\title{
(Appendix 1)
}

- Appendix 1a - survey questions as published (English translated version)

- Appendix $1 \mathrm{~b}$ - survey questions as published (Danish original version) 


\section{Appendix 1a - survey questions as published (English translated version)}

\section{How to fill out the survey}

First print out a questionnaire. Next, fill it, as described below.

Once you have completed it, please send it to:

ME Foreningen, Rådhustorvet 1, 1, 3520 Farum.

Please use a black or blue pen or thin marker.

The answers should be written so that all numbers and crosses should be easy to interpret as shown in the following examples:

\begin{tabular}{|l|l|}
\hline & CORRECT. \\
\hline Please set clear cross. & \\
\hline $\begin{array}{l}\text { If a field is filled out } \\
\text { incorrectly, shade the box } \\
\text { and set a new cross in the } \\
\text { correct box. }\end{array}$ & \\
\hline $\begin{array}{l}\text { Numbers are written within } \\
\text { the fields of the box. }\end{array}$ & \\
\hline $\begin{array}{l}\text { Numbers are corrected by } \\
\text { striking out the wrong } \\
\text { number and write the } \\
\text { correct number above. }\end{array}$ & \\
\hline
\end{tabular}


Quality of Life Survey - ME 2013

By placing a tick in one box in each group below, please indicate which statements best describe your own health state today.

\section{Mobility}

I have no problems in walking about

I have some problems in walking about

I am confined to bed

\section{Self-Care}

I have no problems with self-care

I have some problems washing or dressing myself

I am unable to wash or dress myself

Usual Activities (e.g. work, study, housework, family or leisure activities)

I have no problems with performing my usual activities

I have some problems with performing my usual activities

I am unable to perform my usual activities

\section{Pain/Discomfort}

I have no pain or discomfort

I have moderate pain or discomfort

I have extreme pain or discomfort

\section{Anxiety/Depression}

I am not anxious or depressed

I am moderately anxious or depressed

I am extremely anxious or depressed 
To help people say how good or bad a health state is, we have drawn a scale (rather like a thermometer) on which the best state you can imagine is marked 100 and the worst state you can imagine is marked 0 .

We would like you to indicate on this scale how good or bad your own health is today, in your opinion. Please do this by drawing a line from the box below to whichever point on the scale indicates how good or bad your health state is today.
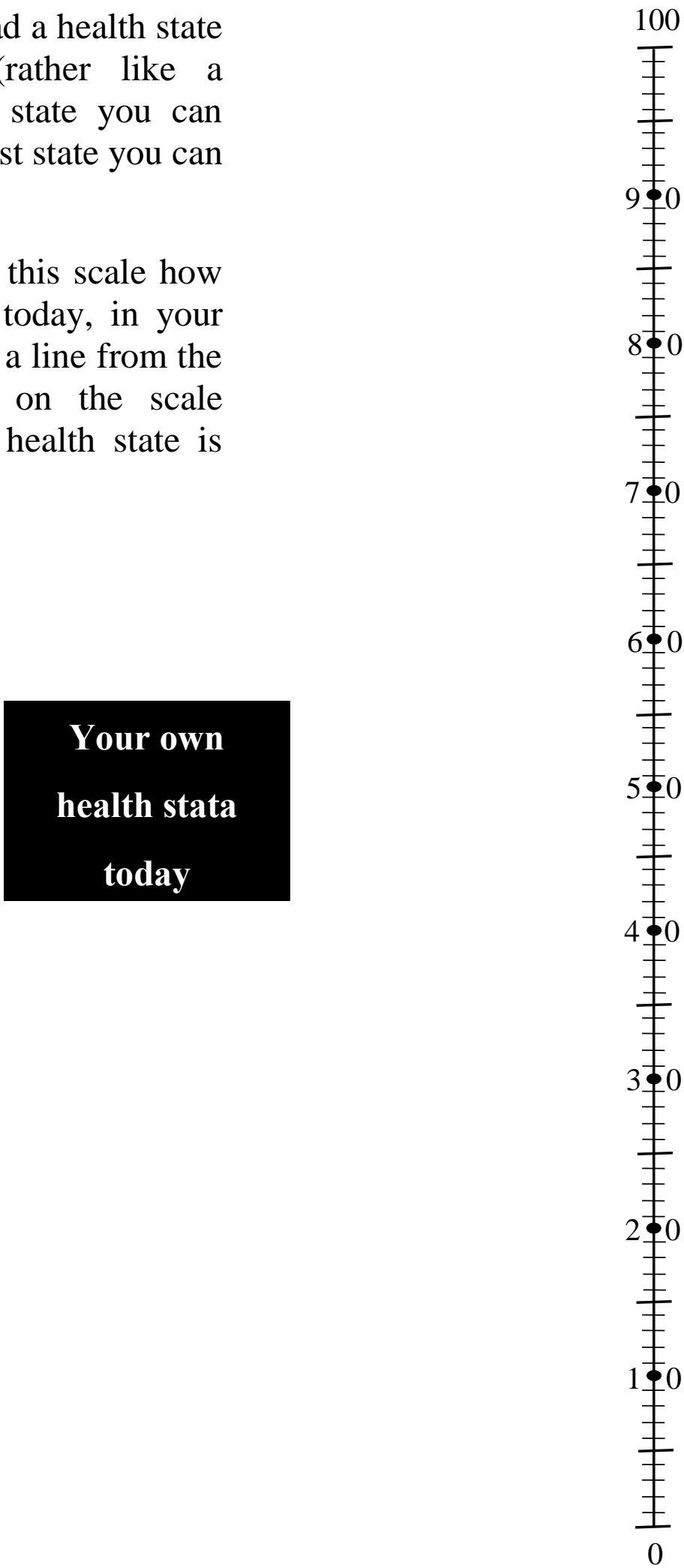

Worst imaginable health state 
Long-term illness and after-effects

Do you have any long-term illness, long-term after effects of injuries, disability or other long-term illness?

(Please only put one X)

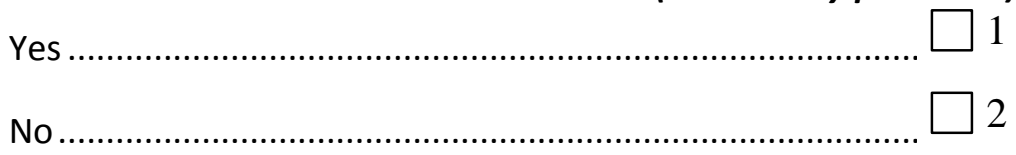

For each of the following diseases and health problems, please indicate whether you have it now or have had it earlier. If you've had it before, please also indicate whether you have after effects.

\begin{tabular}{|c|c|c|c|c|c|}
\hline & $\begin{array}{l}\text { No, that } \\
\text { I never } \\
\text { have }\end{array}$ & $\begin{array}{l}\text { Yes, } \\
\text { that I } \\
\text { have }\end{array}$ & $\begin{array}{l}\text { Yes, that } \\
\text { I have } \\
\text { had }\end{array}$ & \multicolumn{2}{|c|}{$\begin{array}{l}\quad \text { (Only one } X \text { in } \\
\quad \text { every line) } \\
\text { If you have had it } \\
\text { earlier: Do you } \\
\text { still have after } \\
\text { effects? }\end{array}$} \\
\hline & nad & $\underline{110 w}$ & pievious & Yes & No \\
\hline ME / CFS & $\square$ & 72 & 3 & & 72 \\
\hline Allergy (not astma) & & & 3 & $\rightarrow \square$ & \\
\hline Diabetes & & $\square 2$ & 3 & $\rightarrow \square$ & 2 \\
\hline High blood pressure & & $\square 2$ & 3 & $\rightarrow$ & \\
\hline Heart attack & & 2 & & & \\
\hline Angina & & 72 & 3 & $\rightarrow$ & \\
\hline Stroke & & 2 & 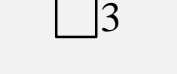 & $\rightarrow$ & \\
\hline $\begin{array}{l}\text { Chronic bronchitis, } \\
\text { emphysema, COPD } \\
\text { (emphysema, COPD) }\end{array}$ & - & & 3 & $\rightarrow$ & 2 \\
\hline Osteoarthritis & & 2 & & $\rightarrow$ & \\
\hline Osteoarthritis & $\square 1$ & 12 & 3 & $\rightarrow$ & 2 \\
\hline Osteoporosis & 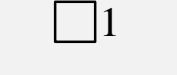 & $\square 2$ & & & $\square 2$ \\
\hline Cancer & $\square 1$ & $\square 2$ & $\sqrt{3}$ & $\rightarrow \square 1$ & $\square 2$ \\
\hline $\begin{array}{l}\text { Migraine or frequent } \\
\text { headaches }\end{array}$ & $\square 1$ & $\square 2$ & ] 3 & $\rightarrow \square 1$ & $\square 2$ \\
\hline Short term mental illness & $\square 1$ & $\square 2$ & $\square 3$ & $\rightarrow \square 1$ & $\square 2$ \\
\hline
\end{tabular}


(for example light

depression or anxiety)

Long term mental illness

or mental disorders

$\begin{array}{lllll}\square 1 & \square 2 & \square 3 & \rightarrow \square 1 & \square 2 \\ \square 1 & \square 2 & \square 3 & \rightarrow \square 1 & \square 2 \\ \square 1 & \square 2 & \square 3 & \rightarrow \square 1 & \square 2 \\ \square 1 & \square 2 & \square 3 & \rightarrow \square 1 & \square 2\end{array}$

Tinnitus

\section{Such all in all ...}

All things considered - how satisfied or dissatisfied are you currently with life? (1 means very dissatisfied and 10 means very satisfied. 88 means "do not know")

(Please only put one $x$ )

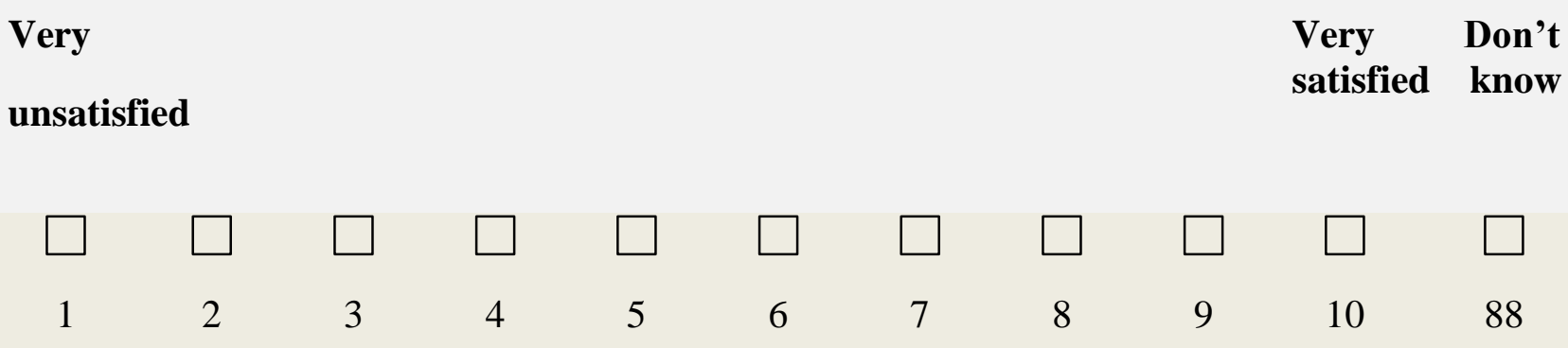

\section{Personal relationships}

Are you..?

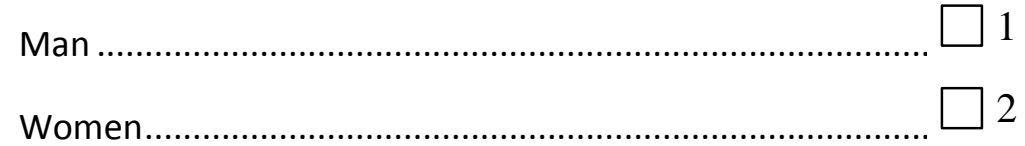

What year were you born?

Write year you were born:: 19 


\section{In which Region do you live..?}

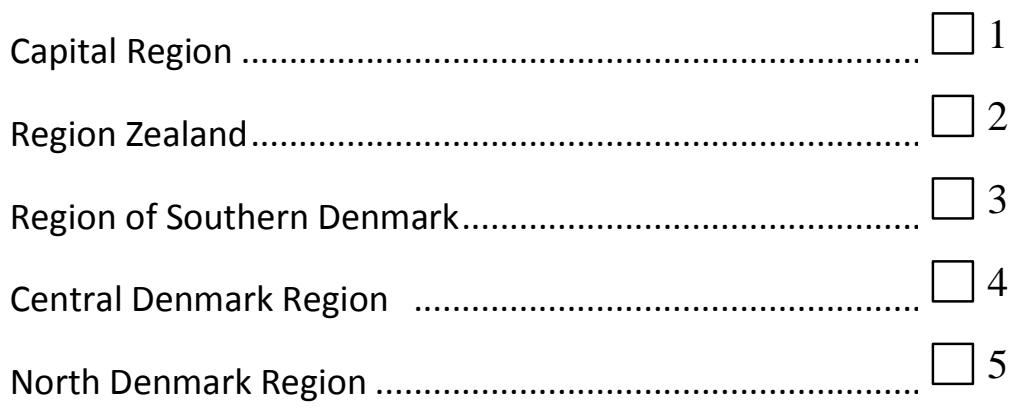

\section{Do you live alone or with others?}

(You may put several X's)

I live alone

I live with my spouse or partner

I live with my parents

I live with a child / children under 16 years

I live with young / young people (16-20 years)

live with other adults above 20 years

\section{What education do you have?}

(Please only put one X)

Still goes to school

7 or fewer years of schooling

8-9 years of schooling

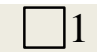

10-11 years of schooling

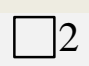

Student, HF-exam (incl. HHX, HTX)

Other (including foreign school)

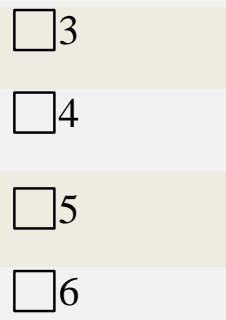


9. grade

10. grade

\section{STX}

HTX

HHX

Trade school basic

EUD (technical school)

HF

Other

(Please only put one X)
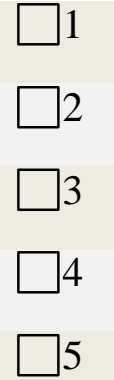

$\square 6$
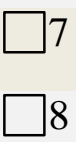

$\square 9$

Have you completed an education beyond basic school- or youth education?

(Please only

put one $X)$

One or more shorter courses (eg specialist worker training, labor rates, etc.)

Vocational education / skilled (eg, office or shop assistants, hairdressers, bricklayers, medical secretary, social and health / assistant, farmer)

Short education, 2-3 years (eg, market economist, police officer, laboratory technician, mechanical engineer, computer science, multimedia, catering manager, dental hygienist)

Medium education, 3-4 years (for example, school, social worker, building technician, nurse, physiotherapist, BSc, educator, bachelor)

Long higher education, more than 4 years (eg MSc, MA., Doctor, psychologist)

Other education

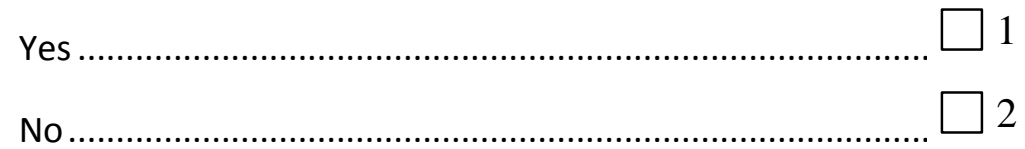


Are you employed?

(Please only put one X)

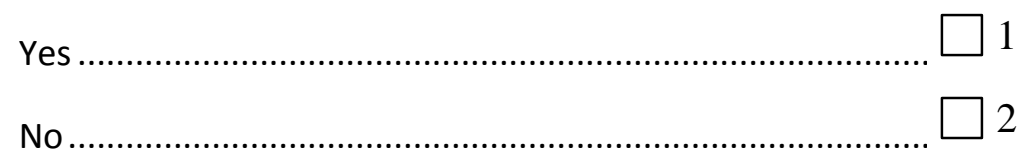

(Please only put one X)

Are you:

Age-related retirement

Disability pensioner

A different type of pension

Pre- retirement, transitional allowance

Unemployment benefits (union)

Sickness benefit

Long term sick (3 months. Or more)

Flex-job

On social security, welfare

During rehabilitation

Other

If other, please write what: 
You have now completed the study.

Please submit your answer to:

ME Foreningen

Rådhustorvet 1,1

3520 Farum

ME Association thank you for your participation which is of great value to our contact with our health politicians.

Sincerely,

Rebecca Hansen

ME Association, Chairman. 


\section{Appendix 1b - survey questions as published (Danish version)}

\section{Sådan udfylder du skemaet}

Først print spørgeskemaet ud. Dernæst udfyld det, som beskrevet nedenunder.

Når du har udfyldt det, så send det til:

ME Foreningen, Rådhustorvet 1, 1, 3520 Farum.

Brug venligst en sort eller blå kuglepen eller tynd filtpen.

Svarene skal skrives ind, så alle tal og kryds skal være nemme at tolke som vist i nedenstående eksempler:

\begin{tabular}{|c|c|c|}
\hline & RIGTIGT & FORKERT \\
\hline Sæt et tydeligt kryds. & & \\
\hline $\begin{array}{l}\text { Hvis et felt er udfyldt forkert, } \\
\text { skraveres den pågældende } \\
\text { kasse og krydset sættes i } \\
\text { den rigtige kasse. }\end{array}$ & 践 & \\
\hline Tal skrives i felterne. & 12 & 2 \\
\hline $\begin{array}{l}\text { Tal rettes ved helt at } \\
\text { overstrege det forkerte tal } \\
\text { og skrive det rigtige tal } \\
\text { ovenover. }\end{array}$ & $\begin{array}{r}4 \\
13\end{array}$ & 19 \\
\hline
\end{tabular}




\section{Livskvalitetsundersøgelse ME 2013}

Angiv, ved at sætte kryds i én af kasserne i hver gruppe, hvilke udsagn, der bedst beskriver din helbredstilstand i dag.

\section{Bevægelighed}

Jeg har ingen problemer med at gå omkring

Jeg har nogle problemer med at gå omkring

Jeg er bundet til sengen

\section{Personlig pleje}

Jeg har ingen problemer med min personlige pleje

Jeg har nogle problemer med at vaske mig eller klæde mig på

Jeg kan ikke vaske mig eller klæde mig på

Sædvanlige aktiviteter (fx.arbejde, studie, husarbejde,

familie- eller fritidsaktiviteter)

Jeg har ingen problemer med at udføre mine sædvanlige aktiviteter

\section{Smerter/ubehag}

Jeg har ingen smerter eller ubehag

Jeg har moderate smerter eller ubehag

Jeg har ekstreme smerter eller ubehag

\section{Angst/depression}

Jeg er ikke ængstelig eller deprimeret

Jeg er moderat ængstelig eller deprimeret 
For at hjælpe folk med at sige, hvor god eller dårlig en helbredstilstand er, har vi tegnet en skala (næsten ligesom et termometer), hvor den bedste helbredstilstand du kan forestille dig er markeret med 100, og den værste helbredstilstand du kan forestille dig er markeret med 0.

Vi beder dig angive på denne skala, hvor god eller dårlig du mener din egen helbredstilstand er i dag. Angiv dette ved at tegne en streg fra kassen nedenfor til et hvilket som helst punkt på skalaen, der viser, hvor god eller dårlig din helbredstilstand er i dag.

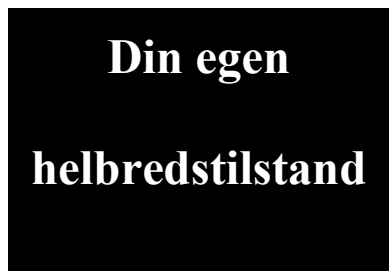

Bedst

tæenkelige

helbredstilstand

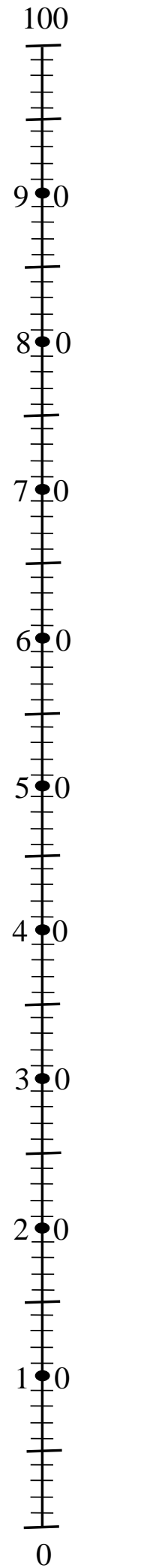

Værst

tænkelige helhredstilstand 
Har du nogen langvarig sygdom, langvarig eftervirkning af skade, handicap eller anden langvarig lidelse?

(Kun ét X)

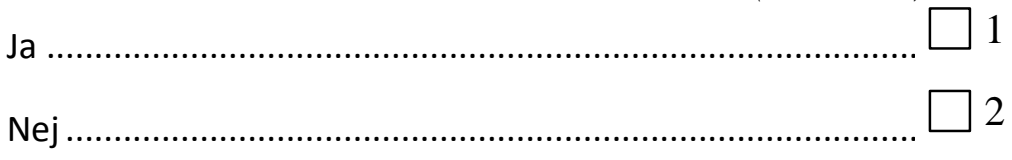

For hver af de følgende sygdomme og helbredsproblemer bedes du angive, om du har den nu eller har haft den tidligere. Hvis du har haft den tidligere, bedes du også angive, om du har eftervirkninger.

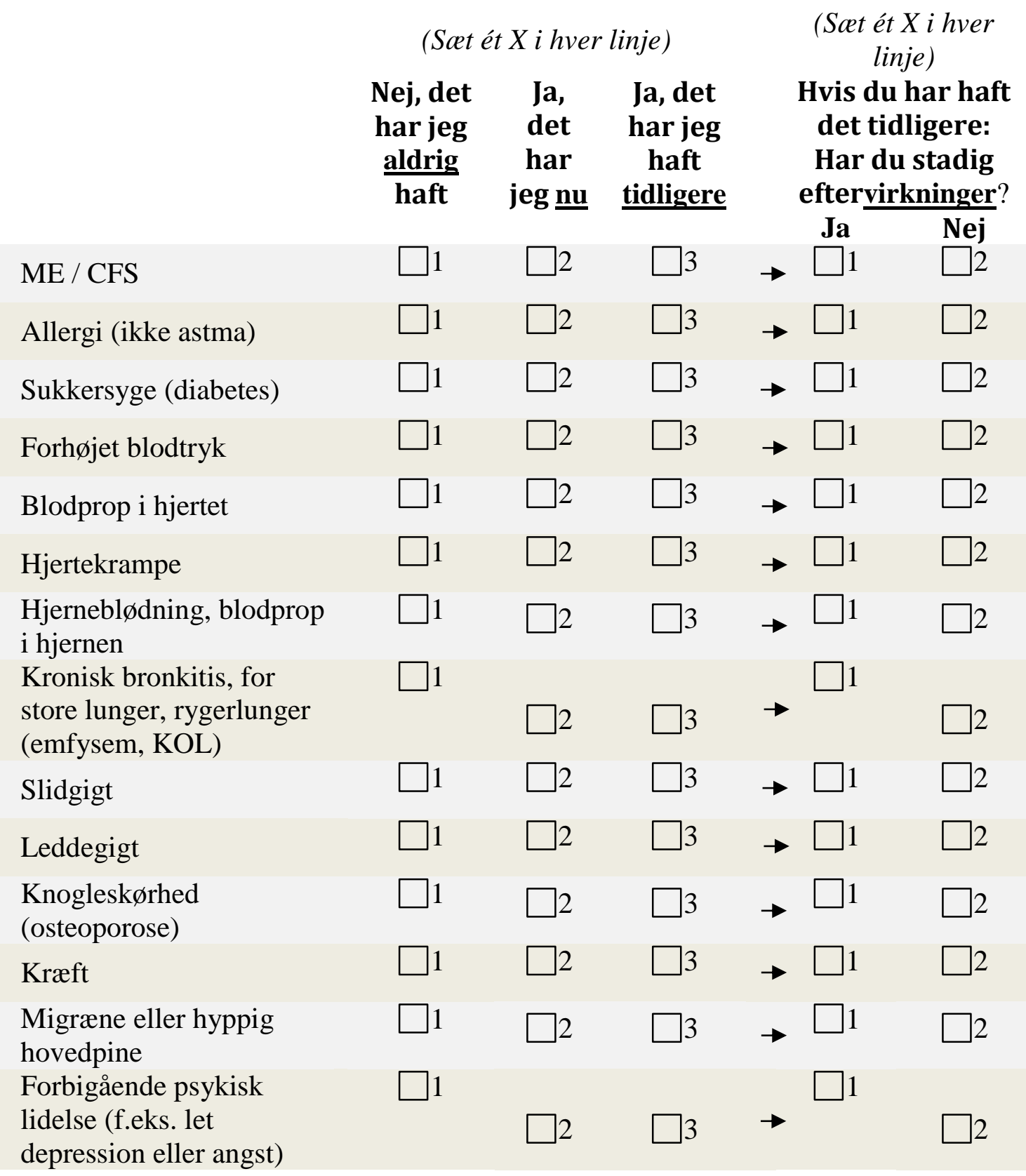


Vedvarende psykisk

sygdom eller mentale
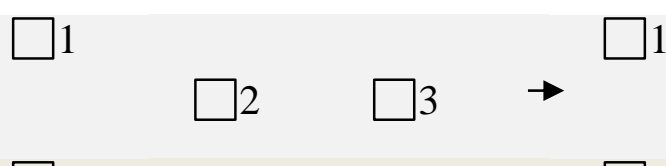

$\square 1$

forstyrrelser

Diskusprolaps eller andre

rygsygdomme

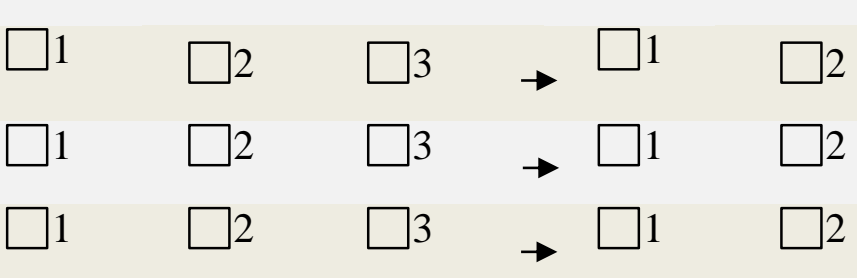

Sådan alt i alt...

Alt taget $\mathrm{i}$ betragtning - hvor tilfreds eller utilfreds er du for tiden med livet? ( 1 betyder meget utilfreds og 10 betyder meget tilfreds. 88 betyder "ved ikke")

(Sat kun ét X

)

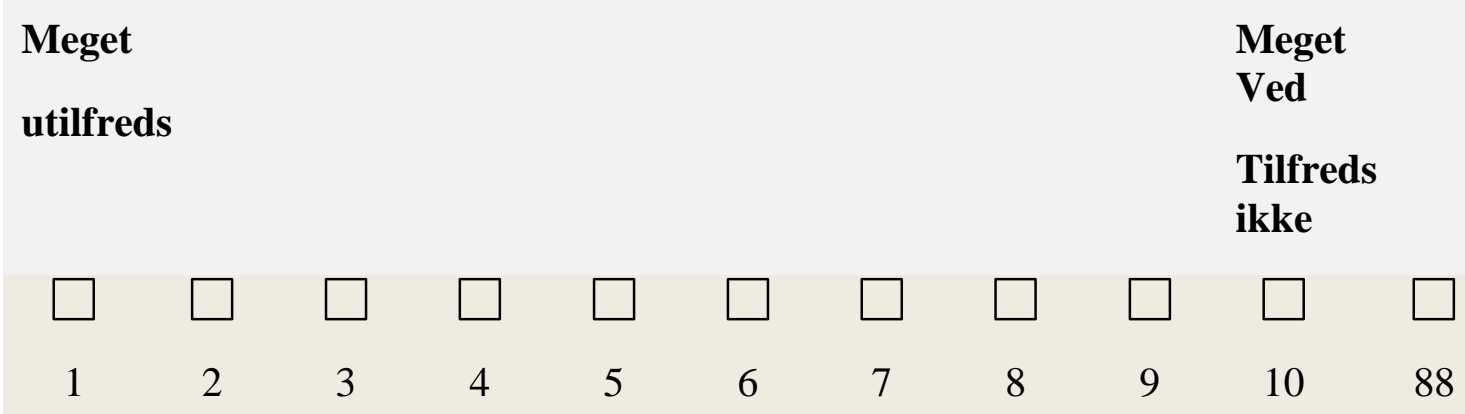

\section{Personlige forhold}

Er du..?

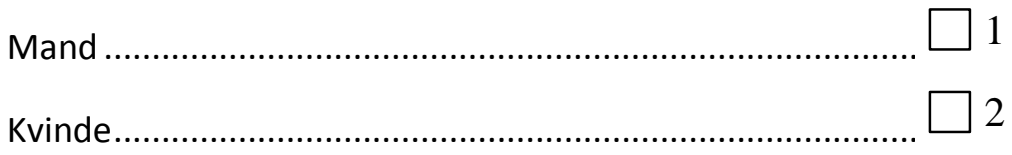

Hvilket år er du født?

Skriv år du er født: 19

I hvilken Region bor du..?

Region Hovedstaden

Region Sjælland 
Region Syddanmark ........................................................... $\square 3$

Region Midtjylland ....................................................... $\square 4$

Region Nordjylland....................................................... $\square 5$

\section{Bor du alene eller sammen med andre?}

(Sæt gerne flere X'er)

(Kun ét X)

Jeg bor alene

Jeg bor sammen med ægtefælle eller samlever

Jeg bor sammen med forældre

Jeg bor sammen med barn/børn under 16 år

Jeg bor sammen med ung/unge (16-20 år)

Jeg bor sammen med andre voksne over 20 år

\section{Hvilken skoleuddannelse har du?}

\section{(Kun ét $x$ )}

Går stadig i skole

7 eller færre års skolegang

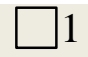

8-9 års skolegang

10-11 års skolegang

Studenter-, HF-eksamen (inkl.

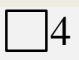

HHX, HTX)

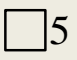

Andet (herunder udenlandsk skole)

Hvilken skole- eller ungdomsuddannelse er du i gang med?

(Kun ét X)

9. klasse

(Kun ét $x$ )

10. klasse

STX 


\section{HHX}

Handelsskolens grunduddannelse

EUD (teknisk skole)

$\mathrm{HF}$

Andet

\section{Har du fuldført en uddannelse udover en skole- eller ungdomsuddannelse?}

Nej

(Kun ét $x)$

Et eller flere kortere kurser (fx specialarbejderkurser, arbejdsmarkedskurser m.v.)

Erhvervsfaglig uddannelse/faglært (fx kontor- eller butiksassistent, frisør, murer, lægesekretær, social- og sundhedshjælper/assistent, landmand)

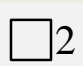

Kort videregående uddannelse, 2-3 år (fx markeds $\varnothing$ konom, politibetjent, laborant, maskintekniker, datamatiker, multimediedesigner, økonoma, tandplejer)

Mellemlang videregående uddannelse, 3-4 år (fx folkeskolelærer, socialrådgiver, bygningskonstruktør, sygeplejerske, fysioterapeut, diplomingeniør, pædagog, bachelor)

Lang videregående uddannelse, mere end 4 år (fx civilingeniør, cand.mag., læge, psykolog)

Anden uddannelse

\section{Er du under uddannelse?}

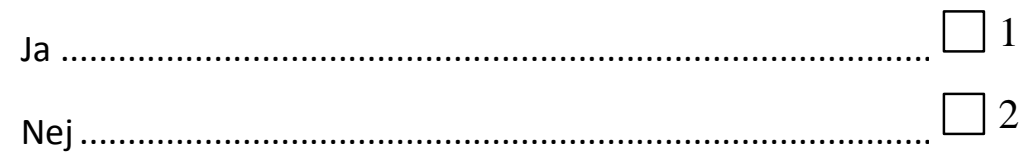

Er du i arbejde?

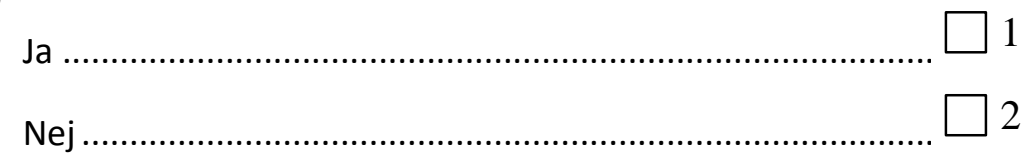

Sat kun 1 kryds:

Er du:

Alderspensionist

Førtidspensionist

Anden form for pension

Efterlønsmodtager, overgangsydelse 


\section{Dagpenge}

Sygedagpenge

Langtidssyg ( 3 mdr. eller mere)

Fleskjob

På kontanthjælp, bistandshjælp

Under revalidering

Andet

Hvis andet, skriv hvad: 


\section{Du har nu afsluttet undersøgelsen.}

Du bedes indsende din besvarelse til

ME Foreningen

Rådhustorvet 1,1

3520 Farum

ME Foreningen takker for din deltagelse som er af stor værdi for vores kontakt til bl.a. sundhedspolitikere.

Med venlig hilsen

Rebecca Hansen

ME Foreningen, formand. 
Appendix 2. Frequencies data-extraction of ME/CFS hospital treated patients from 1994-2013, ICD-10 code G93.3 based on a Danish full population and sample data

Full Population yearly incidence for diagnosis code G93.3 (ME/CFS)

\begin{tabular}{|r|r|r|}
\hline year & Frequency & $\begin{array}{r}\text { Cumulative } \\
\text { Frequency }\end{array}$ \\
\hline 1994 & 44 & 44 \\
\hline 1995 & 46 & 90 \\
\hline 1996 & 46 & 136 \\
\hline 1997 & 63 & 199 \\
\hline 1998 & 53 & 252 \\
\hline 1999 & 40 & 292 \\
\hline 2000 & 27 & 319 \\
\hline 2001 & 24 & 343 \\
\hline 2002 & 37 & 380 \\
\hline 2003 & 43 & 423 \\
\hline 2004 & 43 & 466 \\
\hline 2005 & 30 & 496 \\
\hline 2006 & 32 & 528 \\
\hline 2007 & 27 & 555 \\
\hline 2008 & 26 & 581 \\
\hline 2009 & 31 & 612 \\
\hline 2010 & 24 & 636 \\
\hline 2011 & 30 & 666 \\
\hline 2012 & 35 & 701 \\
\hline 2013 & 44 & 745 \\
\hline
\end{tabular}

Only respondents of the North Denmark Health Survey sample of 2010, merged with hospital data, yearly incidence for diagnosis code G93.3:

\begin{tabular}{|r|r|r|}
\hline year & Frequency & $\begin{array}{r}\text { Cumulative } \\
\text { Frequency }\end{array}$ \\
\hline 1998 & 2 & 2 \\
\hline 2005 & 1 & 3 \\
\hline
\end{tabular}

Source: The Danish National Patient Register, data extracted from Statistics Denmark Researcher Servers. 
